\author{
Ahmet Atasoy, Büşra Demir \\ Sakarya University, Sakarya-Turkey \\ aatasoy@sakarya.edu.tr; dmrbsr43@gmail.com
}

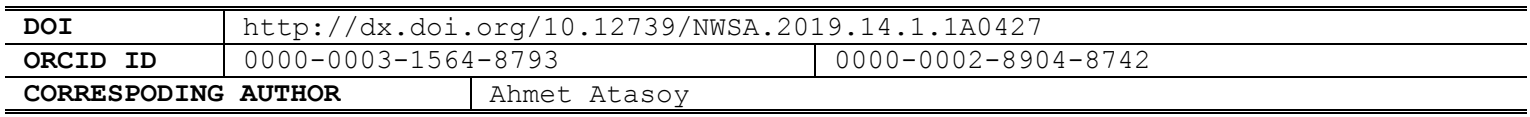

\title{
ZİRKONYUM KARBÜR ESASLI AŞIRI YÜKSEK SICAKLIK SERAMİK KOMPOZİT TOZLARIN METALOTERMIK YÖNTEMLE ÜRETIMI
}

Öz

Günümüzde malzeme bilimi çok gelişmiş olmasına rağmen, yeni teknolojik gereksinimler, var olanlardan farklı yeni nesil malzemelere ihtiyaç duyulmaktadır. Yakın bir gelecekte uzay yolculuğunun gerçekleşebilir olması; aşırı yüksek sıcaklık ortamlarında, çok amaçlı ve tekrarlı kullanilabilir seramik kompozit malzemelerin geliştirilmesine bağlıdır. Aşırı yüksek sıcaklık seramik malzemeleri (AYSS veya Ultra high temperature ceramics-UHTC) $2300^{\circ} \mathrm{C}$ ve üzerindeki ortamlarda kullanılabilir seramikler olarak tanımlanmaktadır. Bu çalışmada, yüksek ergime noktasına sahip, kimyasal ve termal kararlılığı olan AYSS grubuna ait, ZrB ${ }_{2}-\mathrm{ZrC}-\mathrm{SiC}-\mathrm{Al}_{2} \mathrm{O}_{3}$ seramik kompozit tozlarının üretimi, laboratuvar şartlarında, zirkon, borik asit, metalik alüminyum ve grafit başlangıç karışımı kullanılarak araştırılmıştır. Alüminotermik yöntem kullanılmış, başlangıç karışıları ve elde edilen reaksiyon ürünleri SEM, XRD, XRF, TG/DTA gibi analiz yöntemleri ile analiz edilmiştir. Deneysel şartlara bağlı olarak, başlangıç karışımında bulunan zirkon, çok düşük sıcaklıklarda

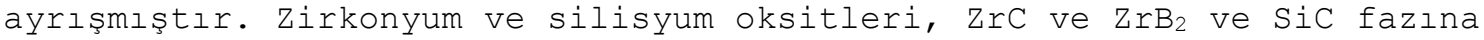
dönüştüğü görülmüştür. Karbür ve borür fazlarının haricinde, proses edilmiş numunelerde $\mathrm{Al}_{2} \mathrm{O}_{3}$ oluşumu da tespit edilmiştir.

Anahtar Kelimeler: Zirkon, Zirkonyum Borür, Karbür, Alümina, Seramik

\section{PRODUCTION OF ZRC BASED ULTRA HIGH TEMPERATURE CERAMIC COMPOSITE POWDERS BY METALLOTHERMIC METHOD}

\section{ABSTRACT}

Although material science is advanced at present time, new technological developments require new generation and different materials that are commercially not available in global market. In order to make long distance space journeys possible in near future, innovation of multipurpose and reusable ceramic composite materials for at high temperature environments are needed. Ceramics that are useable at elevated temperatures as high as $2300^{\circ} \mathrm{C}$ are called Ultra high temperature ceramics (UHTC). In this study, the processing of UHTCS based on $\mathrm{ZrC} / \mathrm{ZrB} \mathrm{B}_{2} / \mathrm{SiC} / \mathrm{Al}_{2} \mathrm{O}_{3}$ ceramic composite that has high melting point, chemical and thermal stability, at the laboratory conditions was investigated using zircon, boric acid, carbon and aluminium powders. Aluminothermic method was chosen, the starting mixtures and the obtained reaction products were analysed using SEM, XRD, XRF and TG/DTA analysis methods. The experimental results showed that, the obtained sample consists of $\mathrm{ZrB}_{2} / \mathrm{ZrC}$ as a matrix phases.

Keywords: Zircon, Zirconium Diboride, Carbide, Alumina, Ceramic

How to Cite:

Atasoy, A. ve Demir, B., (2019). Zirkonyum Karbür Esaslı Aşırı Yüksek Sıcaklık Seramik Kompozit Tozların Metalotermik Yöntemle Üretimi, Engineering Sciences (NWSAENS), $14(1): 17-25$, DOI : 10.12739/NWSA.2019.14.1.1A0427. 


\section{GİRIŞ (INTRODUCTION)}

Çalışmalarına 1960'lı yıllarda başlanılan ileri teknolojik seramikler; yapılarına, kullanım alanlarına ve özelliklerine bağlı olarak farklı şekillerde sınıflandırılmaktadır [1 ve 3]. Bu sınıflandırmada en dikkat çekici malzeme grubu aşırı yüksek sıcaklık ve atmosfer koşullarında kullanılan malzemeler, olup literatürde UHTC olarak tanımlanmakta olan karbür, börür ve nitrür seramikleri (4. ve 5. grup elementlerinin) kapsamaktadır [4 ve 5]. Bu malzemeler, uzay ve havacılık uygulamaları, füze-roket sistemleri ve başlıklarında hipersonik füze gibi aşırı yüksek sıcaklık gerektiren uygulamaları ön plana çıkmaktadır. Termokimyasal ve mekanik özelliklerin geliştirilmesi için hedefli ve ürün bazlı projelere her yıl büyük miktarlarda kaynak aktarılmaktadır. Tablo 1'de aşırı yüksek sıcaklık seramikleri sınıflandırılmış ve bazı özellikleri verilmiştir. Bu malzemeler, karbür, borür ve nitrür bileşikleri olup, yüksek sıcaklıklarda termokimyasal ve termo-fiziksel özellikleri çok yüksek ve kararlıdır [6]. Genel olarak yüksek sıcaklık ortamlarında kullanılmakla beraber, uzay araçlarının yüzey kaplamalarında kullanılmaktadır [7].

Tablo 1. Aşırı yüksek sıcaklık seramiklerin bazı özelıikleri

(Table 1. Some properties of ultra-high temperature ceramics)

\begin{tabular}{|c|c|c|c|c|c|}
\hline Tür & \multicolumn{2}{|c|}{$\begin{array}{c}\text { Kimyasal Formül/ } \\
\text { Malzeme }\end{array}$} & $\begin{array}{l}\text { Kristal } \\
\text { Yapı }\end{array}$ & $\begin{array}{l}\text { Yoğunluk ( } \\
\left.\mathrm{g} / \mathrm{cm}^{3}\right)\end{array}$ & $\begin{array}{l}\text { Ergime } \\
\text { Der. }\left({ }^{\circ} \mathrm{C}\right)\end{array}$ \\
\hline \multirow{7}{*}{$\begin{array}{l}1 \\
\text { Karbürler }\end{array}$} & $\mathrm{TaC}$ & Tantal karbür & Kübik & 14.50 & 3800 \\
\hline & TiC & Titanyum karbür & Kübik & 4.94 & 3100 \\
\hline & $\mathrm{NbC}$ & Niobyum karbür & Kübik & 7.82 & 3500 \\
\hline & $\mathrm{VC}$ & Vanadyum karbür & Kübik & 5.77 & 2810 \\
\hline & SiC & Silisyum karbür & Polimorf & 3.21 & 2820 \\
\hline & $\mathrm{HfC}$ & Hafniyum karbür & YMK & 12.76 & 3900 \\
\hline & $\mathrm{ZrC}$ & Zirkonyum karbür & YMK & 5.56 & 3400 \\
\hline \multirow{6}{*}{$\begin{array}{l}2 \\
\text { Nitrürler }\end{array}$} & TiN & Titanyum nitrür & YMK & 5.4 & 2930 \\
\hline & $\mathrm{H} f \mathrm{~N}$ & Hafniyum nitrür & YNK & 13.9 & 3385 \\
\hline & $\mathrm{NbN}$ & Niyobyum nitrür & Kübik & 8.47 & 2573 \\
\hline & VN & Vanadyum nitrür & Kübik & 6.13 & 2050 \\
\hline & $\mathrm{TaN}$ & Tantalyum nitrür & Kübik & 14.50 & 3800 \\
\hline & $\mathrm{ZrN}$ & Zirkonyum nitrür & YMK & 7.29 & 2950 \\
\hline \multirow{5}{*}{$\begin{array}{l}3 \\
\text { Borürler }\end{array}$} & $\mathrm{ZrB} \mathrm{B}_{2}$ & Zirkonyum borür & Hekzagonal & 6.10 & 3245 \\
\hline & $\mathrm{TiB}_{2}$ & Titanyum borür & Hekzagonal & 4.52 & 2970 \\
\hline & $\mathrm{H} f \mathrm{~B}_{2}$ & Hafniyum borür & Hekzagonal & 11.19 & 3380 \\
\hline & $\mathrm{TaB}_{2}$ & Tantalyum borür & Hekzagonal & 12.54 & 3040 \\
\hline & $\mathrm{NbB}_{2}$ & Niyobyum borür & Kübik & 6.97 & 3050 \\
\hline
\end{tabular}

Aşırı Yüksek Sıcaklık Seramikleri(AYSS) veya İngilizce olarak Ultra High Temperature Ceramics (UHTC) malzemeleri, yüksek ergime sıcaklığı, yüksek elektrik iletkenliği ve mükemmel oksidasyon dirençlerinden dolayı metallerle kıyaslanmayacak farklı özelliklere sahiptir. Kendi aralarında dahi farklı özellikler gösterebilir, örneğin börürlerin oksidasyon direnci karbürlerden daha iyi olmasına rağmen HfC en yüksek ergime derecesine sahiptir. Genel olarak, AYSS malzemelerin kullanım amacına, çalışma ortamı ve sıcaklığına bağlı olarak seçilmektedir. Farklı başlangıç metal, karbür veya börür kullanllarak farklı üretim yöntemleri ile elde edilmektedir. Bu üretim yöntemleri, basınçsız sinterleme [8 ve 9], boro/karbotermal indirgeme nitrürleme [10 ve 12], spark plazma [13], yanma [14] veya metalotermik [15 ve 16] prosesler olabilmektedir. Kullanılan üretim yöntemlerine bağlı olarak elde edilen nihai ürünün termo kimyasal/fiziksel özellikleri değişmektedir. Her bir yöntemin artı ve eksileri bulunmaktadır. Örneğin; karbo termal indirgeme redükleme (KTIN) 
prosesiyle üretilen ürünler ile sol-gel prosesinde elde edilen ürünlerin tane boyutları farklılık göstermektedir.

\section{2. ÇALIŞMANIN ÖNEMI (RESEARCH SIFNIFICANCE)}

Özelikle gelişmiş ülkelerde yeni nesil veya işlenebilir seramik malzemeler konularında yoğun çalışmalar yapılmaktadır. İşlenebilir seramikler konusunda MAX fazlı malzemeler, yeni nesil aşırı yüksek sıcaklık seramikleri konusunda ise zirkonyum nitrür/karbür/borür esaslı seramik kompozit malzemeler ön plana çıkmaktadır. Bu malzemelerin sahip oldukları özellikleri sayesinde mevcut seramik malzemelerin yerini alabilme potansiyeline sahiptirler. Yeni nesil seramik malzemelerin ülkemizin bilimsel araştırma camiasına sunulması önem taşımaktadır. Bu çalışmada, UHTC seramiklerinden olan ZrC, ZrB 2 matris yapısının, daha ekonomik bir üretim yöntemi ile laboratuar şartlarında üretilebilirliği araştırılmıştır. Bu amaçla, zirkon, karbon, metalik alüminyum ve borik asit, stiokiometrik oranda harmanlanarak, başlangıç karışımı olarak kullanılmıştır. Başlangıç karışımının kimyasal, kristal yapıları, prosese bağlı olarak gerçekleşen redüksiyon, karbür ve borür fazları ve reaksiyon mekanizması-sıcaklık-süre parametrelerinin oluşan fazlar üzerine etkileri araştırılmıştır.

\section{DENEYSEL ÇALIŞMALAR (EXPERIMENTAL METHOD-PROCESS)}

Alümünotermik indirgeme/karbürleme ve borlama prosesinde, bor kaynağı olarak borik asit (ETİ Bor-Bandırma), zirkonyum ve silisyum kaynağı olarak zirkon (Eczacıbaşı-Gebze) kullanılmıştır. Karbon kaynağı olarak grafit ve Alüminotermik indirgeme için ise metallik alüminyum kullanılmıştır. Nihai ürün olarak zirkonyum diborür, zirkonyum karbür, silisyum karbür ve alümina oluşacak şekilde, aşağıda verilen 1 no'lu reaksiyona göre başlangıç tozları stiokiometrik oranlarda karışımlar hazırlanmıştır.

$2 \mathrm{ZrSiO}_{4}(\mathrm{k})+\mathrm{B}_{2} \mathrm{O}_{3}(\mathrm{k})+4 \mathrm{Al}(\mathrm{s})+3 \mathrm{C}_{(\mathrm{k})} \rightarrow \mathrm{ZrC}_{(\mathrm{k})}+2 \mathrm{SiC}_{(\mathrm{k})}+\mathrm{ZrB}_{2}(\mathrm{k})+11 / 3 \mathrm{Al}_{2} \mathrm{O}_{3}(\mathrm{k})$

Homojen bir karışım elde etmek amacıyla, başlangıç tozları, zirkon bilye ile 6 saat harmanlama işlemi yapılmıştır. Hazırlanan karışımlar Şekil 1'de verilen deneysel düzeneğinde farklı sıcaklık ve sürelerde, işleme tabi tutulmuştur.

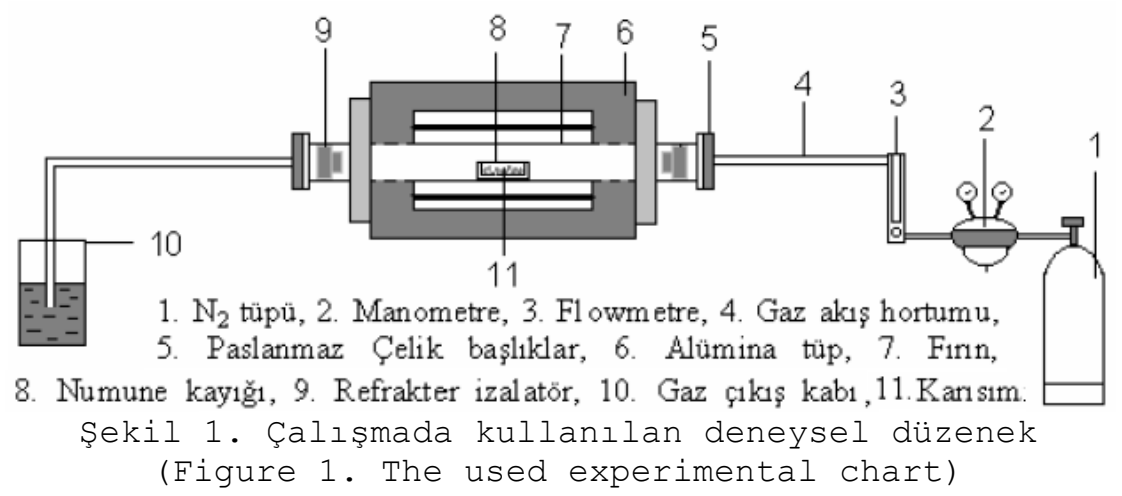

Başlangıç ve proses sonucu elde edilen ürünlerin karakterizasyonu için, termal gravimetri/diferansiyel termal analiz (Netzsch STA 400 Cihazı), X-ışınları difraksiyonu (D/MAX 2200 Rigaku cihazı), taramalı elektron mikroskobu (JOEL 6063), kimyasal (EDS) ve tane boyut analiz yöntemleri kullanılmıştır. Başlangıç ve proses edilen numunelerin X-Işınları kırınımı Cu, $\mathrm{K} \alpha$ ışınları kullanılarak, 0.05 derece/saniye hız ve $10^{\circ}<2 \theta<70^{\circ}$ aralığında XRD grafikleri elde edilmiştir. Numunelerin termal analizi, 25-1450 $\mathrm{C}$ aralığında, 
$10^{\circ} \mathrm{C} /$ dakika ısıtma ve soğuma hızlarında 25ml/dakika argon gaz akışı altında gerçekleştirilmiştir. Deneysel çalışmalarda elde dilen veriler yukarıda sunulmuş ve irdelenmesi aşağıdaki bölümde ayrıntılı olarak ele alınmıştır.

\section{BULGULAR VE TARTIŞMA (FINDINGS AND DISCUSSIONS)}

Hazırlanan başlangıç karışımlarının, X-ışınları analizi Şekil 2'de verilmiştir. Ana faz olarak zirkon, borik asit, karbon ve alüminyum pikleri tespit edilmiştir.

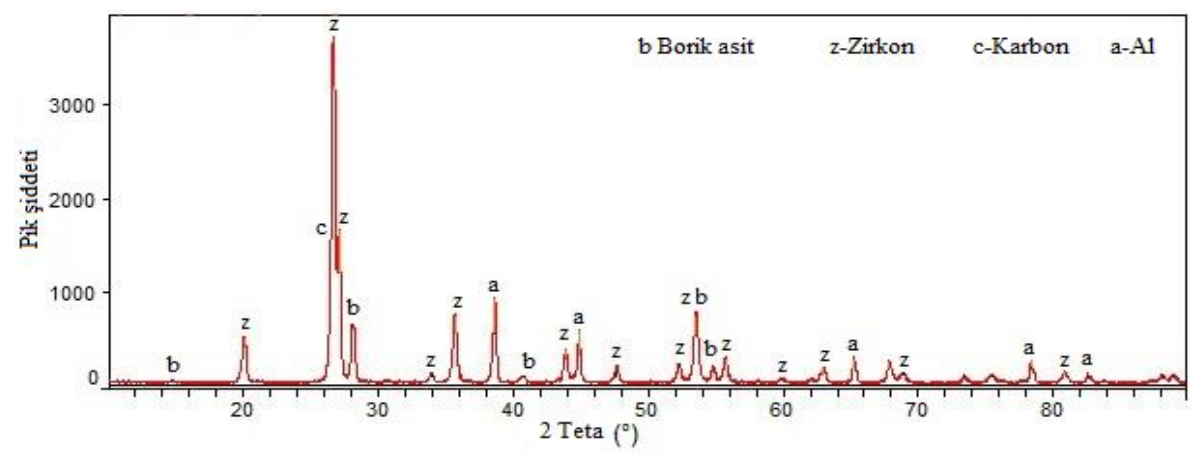

Şekil 2. Hazırlanan karışımın X-ışınları analizi

(Figure 2. X-ray diffraction of the prepared mixture)

Kullanılan başlangıç malzemelerinin termal davranışı tekli veya ikili karışımları aşağıda verilen 2-5 reaksiyonlar ile irdelenmiştir. Bor kaynağı olarak başlangıç karışımına ilave edilen borik asidin termal davranışı hava ortamında incelenmiş ve polimorf özellik sergilemektedir, elde edilen veriler daha önceki çalışmada sunulmuştur [17]. Borik asit 2 nolu reaksiyona göre susuzlaştırılmakta ve bor oksit oluşmaktadır. Metallik alüminyum tozu $650^{\circ} \mathrm{C}$ ergime derecesine sahiptir. Zirkon yüksek sıcaklıkta kararlı bir yapıya sahip olup normal şartlar altında $1700^{\circ} \mathrm{C}$ de 3 nolu reaksiyona göre, zirkonyum dioksit ve silisyum dioksite ayrışmaktadır. Aşırı yüksek sıcaklık seramik malzemeleri kullanılan başlangıç tozlarına bağlı olarak, birçok farklı yöntemle üretilmektedir. Endüstriyel olarak ise, karbotermal indirgeme yöntemi en yaygın olarak kullanılmaktadır. Yöntemle zirkondan, Zr ve Si karbür oluşumu 4 nolu reaksiyon ile verilmiştir. Zirkon, karbürleyici olmaksızın alüminyum ile 5 nolu reaksiyona göre metalik $\mathrm{Zr}$ ve Si indirgenir. Başlangıç tozlarının ikili veya ayrışma reaksiyonları aşağıda verilmiştir.

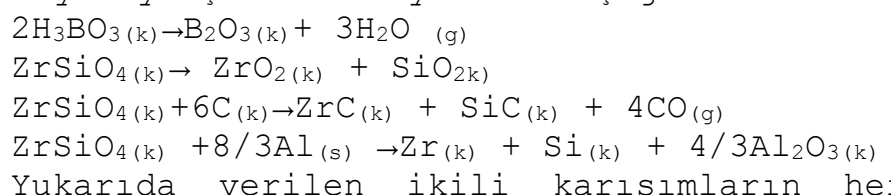

Yukarıda verilen ikili karışımların her biri, basit yapılı reaksiyonlardır. İkili karışımlara, üçüncü ve dördüncü bir reaktanttın eklenmesi, karışımı karmaşık yapılı hale getirmektedir. 1 nolu reaksiyona göre hazırlanan karışımın termal davranışı, ikili karışılardan çok farklı olmaktadır. Ortamda metalik alüminyum bulunması, zirkonun kararlı halini, karışımın reaksiyon türünü, sıcaklığını ve mekanizmasını değiştirmektedir. Proses sürecinde, karışımda eş zamanlı olarak birden fazla ve farklı tepkimler gerçekleşmektedir. Reaksiyon 1 de görüldüğü gibi, reaktantlar ne kadar çok ise tepkime karmaşık (kompleks) bir hal almaktadır. 


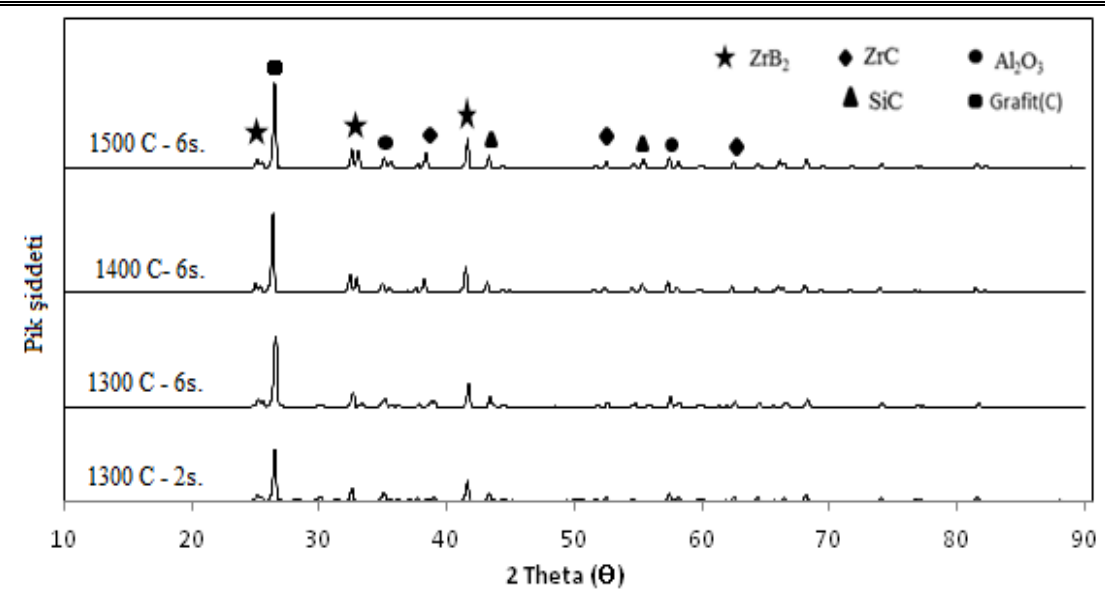

Şekil 3. Farklı sıcaklık ve sürelerde redüklenmiş ve karbüre edilmiş numunelerin X-ışınları analizleri

(Figure 3. XRD pattern of the reduced and carburised samples at different temperature and holding times)

$\begin{array}{cccc}\text { Başlangıç karışımı, farklı sıcaklık ve sürelerde argon atmosferi } \\ \text { altında } & \text { reaksiyona } & \text { tabi } & \text { tutulmuştur. }\end{array}$ indirgeme/karbürleme-borürleme prosesi sonucu elde edilen X-ışınları analizleri Şekil 3'te verilmiştir. XRD desenlerinden de görüldüğü gibi tespit edilen faz ve pik şiddetleri sıcaklık ve süreye bağlı olarak değişmektedir. Sıcaklık ve süreye bağlı olarak yeni fazların oluştuğu görülmektedir. X-Işınları analiz yöntemi ile ortamda belirli bir değerin altında bulunan (⒊5) fazların tespiti mümkün değildir. Reaksiyon sıcaklığın yükselmesine bağlı olarak, ZrB 2 , ZrC, SiC fazlarının pik şiddetlerinde artış görülmektedir. Borüe ve karbür oluşumu, reaksiyon sıcaklığına ve süresine bağlı olarak artmaktadır. Şekil $3^{\prime}$ de $1500^{\circ} \mathrm{C}$ ve 6 saat için, elde edilen reaksiyon fazları ZrB ${ }_{2}$, ZrC, SiC ve $\mathrm{Al}_{2} \mathrm{O}_{3}$ dür. Proses soncunda ortamda kalıntı karbon, reaksiyona girmemiş zirkon fazları tespit edilmemiştir. Üretilen borür ve karbür fazları, yüksek sıcaklık seramikleri olup, elde edilen ürün içerisinde alümina bulunması, karışımı bir UHTC kompozit malzemesi olarak tanımlamaktadır. İkili ZrB ${ }_{2}$ SiC sistemi, UHTC malzemeler arasında önemli bir yer tutmaktadır. Ortamda ZrC ve alümina bulunmasının, nihai ürün üzerinde özellikle oksidasyon davranışına olumlu etki yapabileceği düşünülmektedir.

Deneysel şartlarda başlangıç karışımında zirkon, karbon, borik asit ve metalik alüminyum fazlarından başka herhangi bir faz tespit edilememiş ve tanımlaması yapılamayan pik kalmamıştır. Hazırlanan karışım, $1300^{\circ} \mathrm{C}^{\prime d e} 2$ saat süreyle reaksiyona sokulmuş, oluşan fazlar XRD yöntemi ile tespit edilerek (Şekil 3), başlangıç karışımı (Şekil 2) ile karşılaştırılmıştır. Bu sıcaklık ve sürede, içerisinde reaksiyonun gerçekleşmesine bağlı olarak oluşan ve tespit edilen en önemli fazlardan biri alüminadır. Normal şartlar altında zirkon kararlı bir yapıdır ve $1700^{\circ} \mathrm{C}$ 'de dekompozisyona uğramaktadır. Redükleme-karbürleme-borür prosesi sonucu elde edilen reaksiyon ürünlerinde, alümina fazının tespit edilmiş olması, zirkonun metallik alüminyum ile indirgendiğini ve deneysel şartlarda zirkon, beklenenden daha düşük sıcaklıklarda dekompoze olarak redüklenmektedir. Karışımın termal davranışını görmek amacıyla TG/DTA eğrileri Şekil 4'de verilmiştir. Başlangıç malzemelerinde, sıcaklık karşısında farklı sıcaklık ve değişen hızlarda kütle kaybı görülmektedir. Normal şartlarda bir numunedeki kütle kaybı, ateş kaybı olarak tanımlanır ve ortamda bulunan hidroksitli, karbonatıı ve oksitli yapıya bağlıdır. 
Yapılan deneysel şartlarda ortamda borik asit ve zirkon bulunmaktadır. Geçekleşen kütle kaybı, su buharı oluşumu (borik asit) ve zirkon yapısında bulunan oksijenin uzaklaştırılmasına, diğer bir ifade ile zirkonun metalleşmesine bağlı olarak gerçekleşmiştir. Bu şartlar altında, zirkonyum dioksit ve silika indirgenebilir oksitlerdir. Karışımda gerçekleşen kütle kaybının açıklaması olabilecek üçüncü bir faktör ise oksijen sızıntısına bağlı olarak, karışımda bulunan karbürleyicinin yanmasıyla gerçekleşir. Deneysel çalışmaların argon gazı ortamında gerçekleştiği ve argonun özelliklerinden dolayı bu mümkün değildir. Karışımın kütle kaybı, zirkonun indirgenmesi sonucu gerçekleşmiştir. Her hangi bir karışımda kütle kaybının yanı sıra, kütle kazanımı da görülebilir. Bu durumda ise, fırın atmosferine bağlı olarak karışımda yeni fazların ve ürünlerin oluşması gerekir ve sonucudur. Örneğin, metalik tozların azot ortamında sinterleme sıcaklığı ve süresine bağlı olarak oluşan kütle kazanımı, nitrür oluşumu; oksijen ortamında ise oksit oluşumu olarak tanımlanır. Karışımın TG eğrisine göre, başlangıç karışımı toplam olarak 25 kütle kaybına uğramıştır. Kütle kaybına esas teşkil eden reaksiyonlar, borik asidin susuzlaşmasına ve zirkonun metalik alüminyum ile indirgenmesine bağlı gerçekleşmiştir. Elde edilen TG verilere bağlı olarak, proses, üç aşamaya ayrılmıştır;

I. Aşama, Bor oksit oluşumu: $25-650^{\circ} \mathrm{C}$ aralığında gerçekleşmektedir. Ortamdaki borik asidin susuzlaşması,

II. Aşama, Metalleşme: $650-1150^{\circ} \mathrm{C}$ sıcaklık aralığında gerçekleşmektedir. Oramdaki zirkon be oluşan bor oksidin Al ile metalik forma indirgenmesi ve alümina oluşumu,

III. Aşama Karbür ve Borür oluşumu: $1200-1450{ }^{\circ} \mathrm{C}$ sıcaklık aralığında, kütle kazanımı olarak kendini göstermiştir. Oluşan metalik yapıların ortamdaki karbon ile karbür, bor ile borür oluşturması.

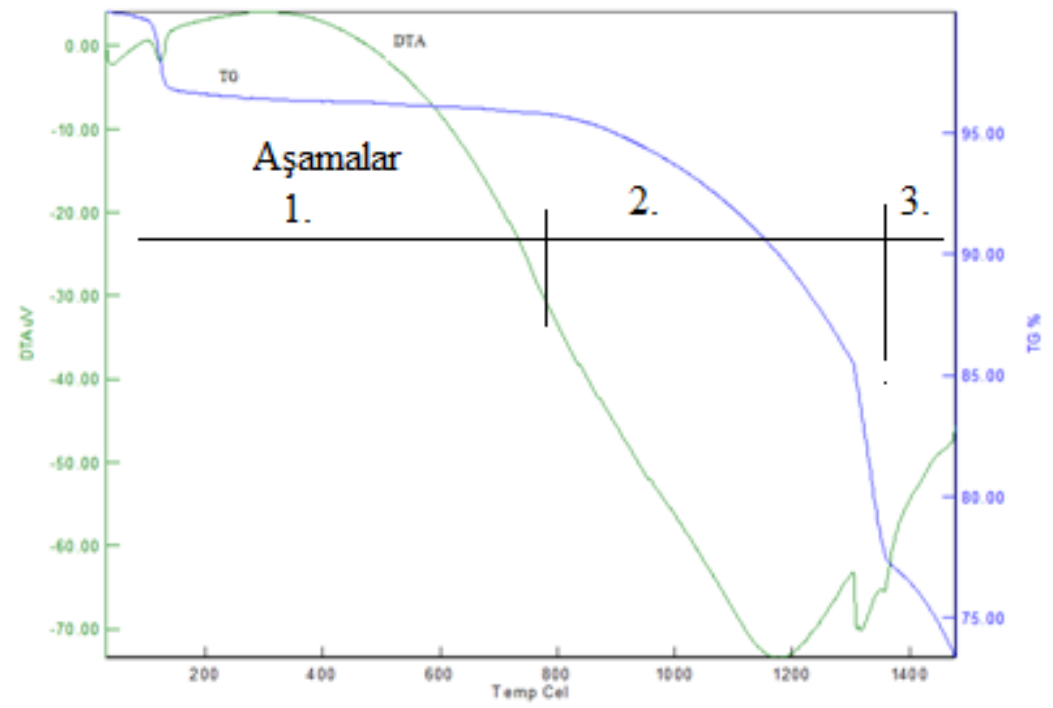

Şekil 4. Başlangıç karışımının elde edilen TG-DTA termogramı (Figure 4. TG-DTA curve of the starting mixture)

Metalotermik reaksiyonlar eksraktif metalürjik proseslerde, özellikle yüksek sıcaklık karbür ve borürlerin üretimlerinde kullanılmaktadır. En yaygın olarak kullanılan indirgeyici metaller Si, Mg, Al ve Ca olarak verilebilir. Prosese bağlı olarak her bir metalin kullanım alanı değişmekle beraber, alüminyum en yaygın kullanılan metaldir. Proses, ekzotermiktir ve büyük miktarlarda ısı oluşumu geçekleşir. İşlem sonucu, oluşan alümina en kararlı oksitlerden biridir ve seramik kompozit malzemelerin kararlılığını artırmak için 
kullanılmaktadır. Bu reaksiyona bağlı olarak oluşan zirkonyum ve silisyum ortamda bulunan karbon ile reaksiyona girerek karbür fazları oluşmuştur. Daha düşük sıcaklıkta oluşan bor oksit $\left(\mathrm{B}_{2} \mathrm{O}_{3}\right)$, ekzotermik reaksiyona bağlı olarak elementel forma indirgenmiştir ve oluşan

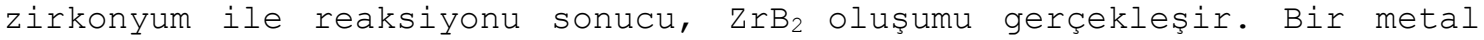
oksit ve indirgeyiciden oluşan ikili bir sistemin reaksiyon mekanizmasını açıklamak ve anlamak basittir. Dört farklı reaktantlardan oluşan sistemlerin reaksiyon mekanizması karmaşık ve birden fazla mekanizmalarla açıklanabilmektedir. Termal analiz yöntemlerinden DTA analizi ile karışımda proses esnasında oluşan reaksiyon türlerini (endotermik ve ekzotermik reaksiyon) ve bu reaksiyonların gerçekleşme sıcaklığı tespit edilir. Şekil 4'de verilen DTA eğrisinde görüldüğü gibi, kullanılan başlangıç karışımı farklı sıcaklıklarda endotermik ve ekzotermik pikler göstermektedir. 1. endotermik pik, $180^{\circ} \mathrm{C}$ de gerçekleşmiştir ve borik asidin susuzlaşmasına bağlı olarak oluşmuştur. Bor kaynağı olarak kullanılan borik asit $\mathrm{H}_{3} \mathrm{BO}_{3}$ formundadır ve bor oksit yapısına dönüşüm göstermesi birden fazla aşamada gerçekleşmektedir. Yapılan çalışmalarda borik asidin susuzlaştırılması ve kararlı bor oksit oluşum sıcaklığı 25$650^{\circ} \mathrm{C}$ gerçekleşmektedir. Bu özelliği ile polimorf yapı sergilemektedir [17]. 2. endotermik pik, karışımda bulunan zirkonun ayrışma reaksiyonuna bağlı olarak oluşan silika, metalik içerik ile metalleşmesine bağlı olarak $1150^{\circ} \mathrm{C}$ gerçekleşmiştir. 3. endotermik pik ayrışmaya bağlı olarak oluşan zirkonya yaklaşık $1320^{\circ} \mathrm{C}$ de metalleşmiştir. DTA eğrisi üzerinde, iki faklı sıcaklıkta ekzotermik pik göstermektedir. $1300^{\circ} \mathrm{C}$ de tespit edilen ekzotermik piklerin silisyum ve zirkonyum karbür oluşumuna ve $1400^{\circ} \mathrm{C}$ de ise zirkonyum borür oluşum sıcaklıklarını vermektedir. Bu nedenlerden dolayı, başlangıç karışımları metalik içeriği oluşturan alüminyum ile beraber sıvı fazları oluşturmaktadır. Diğer reaktantlar ise ortamda katı formda bulunmaktadır. Bu şartlar altında, reaksiyon 1, sıvı-katı reaksiyon mekanizması prosesi kontrol etmektedir.
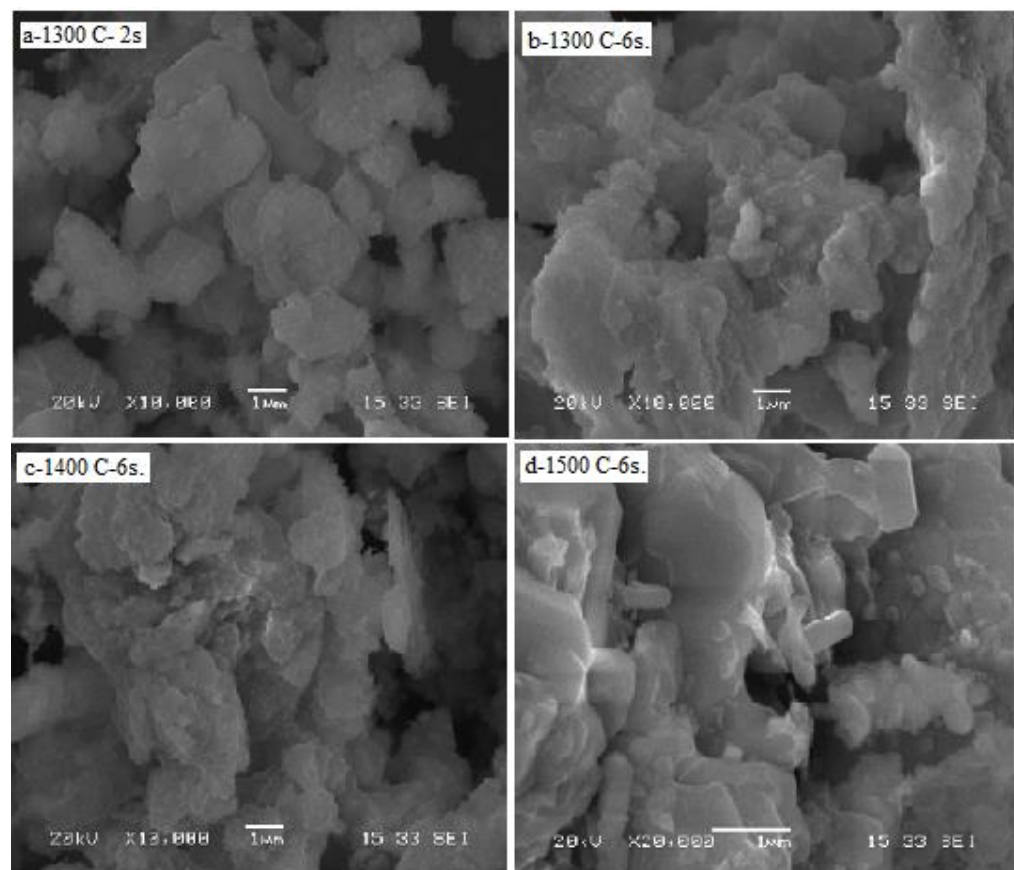

Şekil 5. Elde edilen reaksiyon ürünlerinin SEM görüntüleri (Figure 5. SEM micrograph of the obtained powders) 
Taramalı elektron mikroskobu (SEM), kullanılan ve elde edilen ürünlere ait yapı ve morfolojilerinin irdelenmesinde çok önemli bir karakterizasyon yöntemidir. Şekil 5'te farklı sıcaklık ve sürelerde elde edilmiş numunelerin görüntüleri verilmiştir. Kullanılan deneysel şartlara bağlı olarak SEM görüntüleri farklılık göstermektedir.

\section{SONUŞ VE ÖNERILER (CONCLUSION AND RECOMENDATIONS)}

Bu çalışmada, alüminotermik yöntem ile daha ekonomik zirkonyum, silisyum ve bor kaynağı kullanılarak, zirkonyum karbür esaslı aşırı yüksek seram kompozit tozunun üretimi gerçekleştirilmiştir. Üretilmiş toz numuneler incelendiğinde, ZrC fazının yanı sıra, $\mathrm{SiC}, \mathrm{Al}_{2} \mathrm{O}_{3}$ ve $\mathrm{ZrB}_{2}$ içermektedir. Bu fazlardan dolayı, AYSS kompozit numunelerinin, HIP veya SPS gibi yöntemlerle sinterleme işleminden sonra termo kimyasal ve termo-fiziksel özeliklerinin araştırılacaktır. Gelecekte hipersonik araçlarda uçuş, yanma ve itme sistemlerinde aşırı yüksek sıcaklık seramiklerinin (AYSS) kullanımının önemli derecede artacağı düşünülmektedir. Çalışmaların başarılı olabilmesi, UHTC kompozitlerinin daha ekonomik ve çoklu (tekrarlı) kullanımlarına bağlıdır. Halen kullanılan monolitik, ikili seramiklerin yerini kompozit UHT seramiklerin alacağı ve özellikle oksitlenme mekanizmaları/kontrol edilebilme çalışmalarının ön plana çıkacaktır.

\section{NOT (NOTICE)}

Bu çalışma, 21-23 Eylül 2017 tarihleri arasında Bayburt'ta gerçekleştirilen International Conference on Advanced Engineering Technologies (ICADET-17) konferansında sunulmuştur.

\section{KAYNAKLAR (REFERENCES)}

[1] Fahrenholtz, W.G., Hilmas, G.E., Talmy, I.G., and Zaykoski, J.A., (2007). Refractory Diborides of Zirconium and Hafnium, J American Ceramic Society. Cilt:90, No:5, ss:1347-1364.

[2] Paul, A., et all., (2012). UHTC Composites for Hypersonic Applications. American Ceramic Bulletin. Cilt:91, ss:22-29.

[3] Tang, S. and Hu, C., (2017). Design, Preparation and Properties of Carbon Fiber Reinforced Ultra-High Temperature Ceramic Composites for Aerospace Applications: A Review, J Materials Science and Technology. Cilt:33, ss:117-130.

[4] Fahrenholtz, W.G., Hilmas, G.E., Chamberlain, A.L., and Zimmermann, J.W., (2004). Processing and Characterisation of ZrB $\mathrm{B}_{2}$-based Ultra-High Temperature Monolithic and Fibrous Monolithic Ceramics. J Materials Science. Cilt:39, ss:5951-5957.

[5] Talmy, I.G., Zaykoski, J.A., and Opeka, M.M., (2010). Synthesis, Processing and Properties of $\mathrm{TaC}^{-} \mathrm{TaB}_{2}-\mathrm{C}$ Ceramics, J European Ceramic Society. Sayı:30, ss:2253-2263.

[6] Mitra, R., Upender, S., Mallik, M., Chakraborty, S., and Ray, K.K., (2009). Mechanical, Thermal and Oxidation behaviour of Zirconium Diboride Based Ultra-High Temperature Ceramic Composites, Key Engineering Materials. Cilt:395, ss:55-68.

[7] Bellosi, A. and Scatteia, L., (2008). Processing and Properties Of Ultra-High Temperature Ceramics for Space Applications, Materials Science and Engineering: A. Sayı:485, ss:415-421.

[8] Ghaffari, A., Faghihi-Sania, A., Golestani-Fardb, F., and Ebrahimi, S., (2013). Pressureless Sintering of Ta.8 Hfo.2 C UHTC in the Presence of MoSi2, Ceramics International. 39, ss:19851989 .

[9] Sciti, D., Silvestroni, L., and Bellosi, A., (2006). HighDensity Pressureless-Sintered HfC-based Composites, J American Ceramic Society. Cilt:89 Sayı:8, ss:2668-2670. 
[10] Setoudeh, N. and Weham, N.J., (2014). Carboniridation of Mechanically Activated Mixtures of Zircon And Carbon, J Alloys and Compounds. Cilt:586, ss:730-735.

[11] Deng, X., ve ark., (2015). Preparation and Characterisation of $\mathrm{ZrB}_{2}$-SiC Composite Powders from Zircon Via Microwave-Assisted boro/carbothermal Reduction, Ceramics Internetional. Cilt:41, ss:1419-1426.

[12] Ni, D., Zhang, G., Kan, Y., and Wang, P., (2010). Hot Pressed $\mathrm{HfB}_{2}$ and $\mathrm{HfB}_{2}-20 \%$ SiC Ceramics Based on $\mathrm{HfB}_{2}$ Powder Synthesised by Borothermal Reduction of $\mathrm{HfO}_{2}$, Inter $\mathrm{J}$ Applied Ceramic Technology. Cilt:7, Sayı:6, ss:830-836.

[13] Monteverde, F., Melandri, C., and Guicciardi, S., (2006). Microstructure and Mechanical Properties of an $\mathrm{HfB}_{2}+30 \mathrm{vol}$. oSiC Composite Consolidated by Spark Plasma Sintering, Materials Chemistry and Physics. Cilt:100, ss:513-519.

[14] Licheri, R., Orru, R., Musa, C., and Cao, G., (2008). Combination of SHS and SPS Techniques for Fabrication of Fully Dense Composite, Materials Letters. Cilt:62, ss:432-435.

[15] Ran, S., Vanderbiest, O., and Vlengels, J., (2010). ZrB 2 Powders Synthesis by Borothermal Reduction, J American Ceramic Society. Cilt:93, Sayı:6, ss:1586-1590.

[16] Jaalaly, M., Tamizifar, M., Bafghi, M.S., and Gotor, F.J., (2013). Mechanochemical Synthesis of $\mathrm{ZrB}_{2}-\mathrm{SiC}-\mathrm{ZrC}$ Nano Composite Powder by Metallothermic Reduction of Zircon. J Alloys and Compounds. Cilt:581, ss:782-787.

[17] Atasoy, A., (2010). The Aluminothermic Reduction of Boric Acid, Int. J. Refractory Metals and Hard Materials. Cilt:28, ss:616622 . 